Dewi Budhiartini Juli Isnaini

\title{
CONSUMER PERSPECTIVE ON PUBLIC TRANSPORT: THE MEDAN-PEMATANG SIANTAR ROUTE AS A CASE STUDY
}

\begin{abstract}
Development of public transportation is meant to bridge the divide between cities and encourage development results. The inter-city transportation opens up opportunities for the inter-city trade, reduces costs and increases labor mobility, thereby promoting the inter-city development opportunities. This study uses the factor and cluster analyses. Analysis of factors is performed to determine the most dominant factors. The cluster analysis is used to identify the advantages and disdvantages of five modes of transport, namely taxi, trade rail, economy bus, mini bus, and executive bus. This study aims to determine the perception of users of Medan-Pematang Siantar route service. The results of this study show that there are five dominant factors that are considered before the service users decide on the mode of transport to use, namely the comfort factor, which is the most important consideration, followed by the time factor, cost factor, accessibility factor and safety factor.
\end{abstract}

Keyword: consumer's perspective, public transportation, inter-city trade

\section{Introduction}

Development is a continuous process and it involves a plan to improve people's lives in various aspects. Transportation is an important aspect of development. Most aspects of human life involve transportation. Transportation develops along with the progress in human life and culture.

Development of the public transportation bridges the gap between cities and promotes development. The inter-city transportation provides opportunities for trade between cities and increases labor mobility, thereby promoting inter-city development opportunities.

In cities, transportation supports the achievement of labor or workplace needs, school needs, public needs and rural needs. In addition to meeting the needs of people, transportation is required to move goods from one place to another. Transportation has a direct impact on trade. It results in increased trade and inter-regional communications [1].

A study [2] mentions the development objectives of the land transportation department from 2005-2009, which focused on the preservation and development of transportation: (1) rehabilitation of roads is a priority in the development of road transportation; (2) development of municipal transportation, especially in major cities, is primarily concerned with the development of rail-based road transport, enabling the reduction of using the private cars and improving the efficiency of public transport; (3) development of the railway transportation is primarily concerned with the restoration of railway infrastructure to the normal state level, which involves maintenance activities to improve safety and ensure smooth operation.
Standard transportation facilities and good highway network are required to achieve efficient modes of transportation. The Medan-Pematang Siantar route connects two cities located in the North Sumatra region, with a distance of $120 \mathrm{~km}$ between them. The population of Medan City is estimated at two million people and it is a city that functions as the center of trade, tourism and government of North Sumatra. Pematang Siantar City has a population of around 300 thousand people and it is a city that functions as a trade center; the city is a transit to tourist attraction sites in cities such as Parapat, Berastagi and Samosir Island. Both cities are closely linked, both economically and culturally.

Medan-Pematang Siantar transportation route is crowded with various modes of public transportation, but the most common is bus transportation. Buses full of passengers are often seen since many people depend on the bus transportation, which is an economical mode of transport. Taxis are also common along the MedanPematang Siantar route, but they are often involved in accidents due to speed exceeding the limits stipulated by traffic regulations. However, other modes of transportation, such as executive trains and buses, are not considered by many passengers. In addition, the movement of people and goods between the cities of Medan and Pematang Siantar is increasing from year to year. This causes the public transportation needs to increase, as well.

The phenomenon described above attracts the attention of researchers. This study evaluates the transportation services between the cities of Medan and Pematang Siantar, as well as the perception of users of public transportation services regarding the reason for choosing a particular 
public transportation mode along the Medan-Pematang Siantar route.

\section{Conceptual framework}

\subsection{Consumer perception}

To understand a person's perception in the selection of any of the transport services listed in this chapter, it is important to understand consumer behavior towards other services. Therefore, the user's perception of public transport services is described based on the knowledge of the consumer behavior.

\subsubsection{Understanding consumer perception}

A study suggests that companies that truly understand consumer perceptions of external properties, pricing and different ad approaches have a great advantage over their competitors [3]. Some studies indicate that understanding the consumer and the process of consumption of goods are important in analyzing user decisions [4-5].

The ability to keep the user (consumer supremacy) is the underlying principle of all the marketing activities [6]. This principle emphasizes that the consumer is the goal of marketing. A study [7], derived from [4-5], pointed out that marketing is the whole business dealings seen from the point of view of the end-user.

User behavior is defined as a person's decision-making process and physical activity involving the processes of assessing, acquiring and using goods and services [8]. Furthermore from [9], indicated that a persons behavior is shaped by planning, buying and usage of economic goods and services.

In addition, [8] stated that individuals always choose the goods or services they deem to be capable of providing maximum satisfaction in the process of evaluating goods and services.

Consumer perception is also defined as the study of buying and exchange processes involving procurement and disposal of goods, services, experiences and ideas. A user cannot avoid the exchange process, i.e. all the resources are exchanged between the two parties [4-5]. The American Marketing Association, as cited by [10], defines the user behavior as the dynamic interaction of affect and cognition, behavior and surrounding events by which people carry out the exchange aspects of their lives.

From the explanations of experts, one can conclude that the behavior of a person, group or organization, related to obtaining and using goods or services, may be affected by the environment.

According to [11], the most appropriate source of marketing in a service output tends to be on personal resources. The personal resources are more important in influencing the purchase of a single service.

\subsection{Transport services}

\subsubsection{Understanding public transport}

The public transport refers to public service vehicles used to transport passengers who pay certain fares as payment for the trip. Vehicles used in public transport may be owned and maintained independently or by public bodies, such as local governments, municipalities and private companies, either for social or profit-making purposes.

The public transport is one of the the most important parts of a society, as transport is closely related to community locations and activities, as well as the availability of goods and services. Transport is defined as the transfer of persons and goods from one place to another for a particular purpose. Therefore, it is clear that transport is only a tool to overcome distance, which geographically separates human needs.

Transportation services provided by transportation services company is a type of service output. In general, service outputs have four basic forms: real, holdable, inseparable from entrepreneurs and cannot be saved.

Transport is defined as a process of transfer and this process cannot be separated from the need for supporting tools to ensure smooth transition at the desired time [12].

\subsubsection{Transport service level}

The service level is a measure of the overall performance of a service and it influences the perceptions of service users. Service level is a basic element of transport, since users are attracted to use a transport service based on travel behavior. The main factor used in assessing the level of transport services can be divided into three groups, namely [13]:

Elements that affect service users, such as operating speed, trust and safety.

Elements of quality of service account for qualitative services, including comfort, passenger perception, beauty and cleanliness.

Fares that must be paid by the service user for the service.

\subsection{Transport modes}

\subsubsection{Definition of the transport mode}

To analyze the transportation demands, [5] reviewed three key components of the transport mode: Transport mode as a representative of various transport elements (T), activity modes as a representative of socioeconomic activity (A), and transport flow pattern as a representative of movement of goods and persons according to origin (F). The interactions of the three components are shown in Figure 1. 


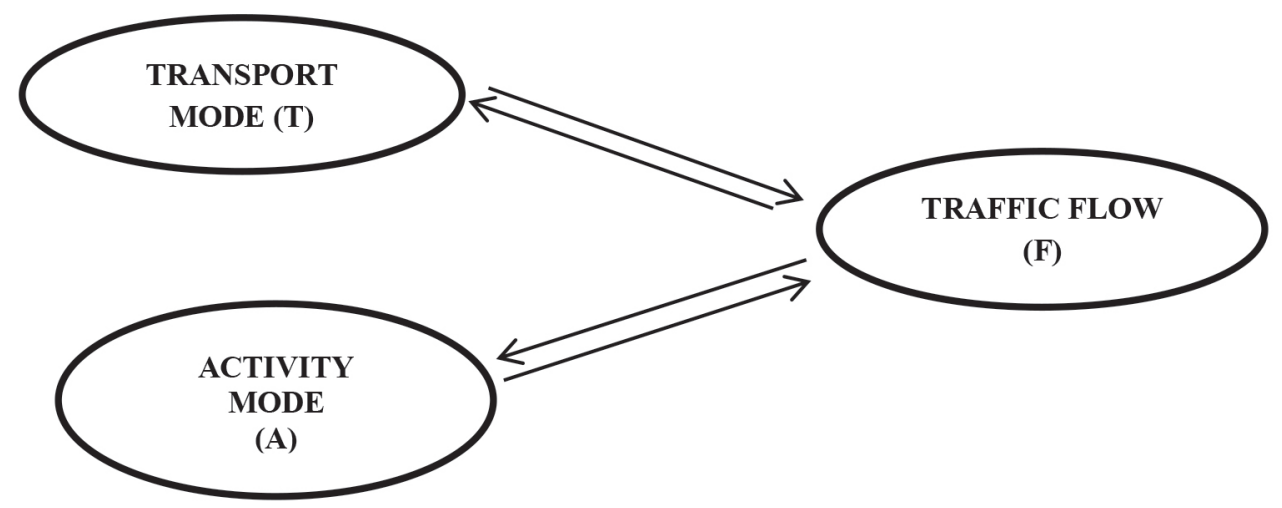

Figure 1 Basic Relationship between the Components of Mode of Transport [5], (A) stands for Activity Mode, (T) stands for Transport Mode, (F) stands for Traffic Flow

Figure 1 shows that traffic flow pattern (F) is strongly influenced by the transport mode (T) as supply and activity mode (A) as demand. In contrast, (F) through its serviceability may also affect (A) in providing the service.

Likewise, ( $\mathrm{T}$ ) changes based on (F), for example by building a new road. An issue that attracts attention while analyzing transport problems is that there is no direct relationship between ( $\mathrm{T})$ and (A). If they influence each other, then a change in (T) or (A) would result in a change in $(\mathrm{F})$, which in turn affects one or both of them. This situation will result in balance and at all times lead to a state of mutual influence.

Transport service users, in selecting a particular mode of transportation, may be influenced by the situation or personal impulse [14]. Influence of the situation can be explained by the service level of the modes of transport and environmental factors at ta ravel time. On the contrary, personal impulses are heavily influenced by lifestyle aspirations and basic needs that make up a person's motivation to travel. Further, regarding situational influence, there is a direct factor that influences the service level of the transport service operator. According to [12], this factor is called factor of consideration in determining the level of services, i.e. time factor, travel cost factor, distance factor and societal income.

Environmental factors, such as place factor (comprising distance and facilities needed for transport services), are indirect factors influencing service operators and users of transport services [15]. The place factor is an added value offered by transport operators to transport service users according to the mode of transportation provided. The ecommerce environment factor is also categorized as an external factor because of the nature of the operators of the transport services.

From the above explanations, to obtain with certainty the reason for choosing the various transport modes in the Medan-Pematang Siantar route by passengers, it is necessary to consider the form of service offered by each passenger transport mode (as part of the internal factors), as well as the travel requirements and motivation influenced by the socio-economic level of the passenger (as part of the external factor).

\subsubsection{Modes of public transport}

The available modes of public transport in various places in Indonesia are categorized as follows:

- Big Bus (city bus)

- Simple bus (micro bus)

- Inter city bus

- Rental car

- Public passenger vehicles (taxis)

- Freight transport vehicles

In operation, public transport, according to Government Regulation of the Republic of Indonesia No. 44 of 1993, can be distinguished as follows:

- Transport of people in regular and irregular routes;

- Transport of people that are not in the path.

Intercity transport takes place from one city to another using public buses that have organized routes. Some transport service operators pick up passengers from door to door. The big bus is a bus equipped with 35 to 102 seats excluding the seat of the driver and without the carriage of goods. The simple bus is a bus equipped with 24 seats excluding the driver's premises and without freight services. The small bus is a bus equipped with 9 to 20 seats excluding the seat of the driver and without the carriage of goods.

\section{Analysis of public transportation facilities along the Medan-Pematang Siantar route}

Analysis of the Medan-Pematang Siantar route's public transport facilities is done under the following subheadings.

\subsection{Dominant factors}

Result of the data processing regarding the service perception of users is obtained by collecting users' data before taking a trip using public passenger transport from Medan to Pematang Siantar. From that data, there are 5 factors comprising a set of initial variables. 
Table 1 Matrix factor loading analysis

\begin{tabular}{|c|c|c|c|c|c|}
\hline \multirow{2}{*}{ Variable } & \multicolumn{5}{|c|}{ Factor } \\
\hline & Comfort & Accessibility & Cost & Time & Safety \\
\hline $\mathrm{X} 1$ & .4829 & -.0799 & .2075 & -.3117 & .0352 \\
\hline $\mathrm{X} 2$ & .0332 & .7077 & .2121 & .0869 & .1696 \\
\hline X3 & .5261 & .0910 & .1367 & .3615 & .1204 \\
\hline $\mathrm{X} 4$ & .0019 & .7114 & .0645 & -.3272 & -.0488 \\
\hline X5 & .5776 & -.0831 & .2654 & -.0521 & -.0100 \\
\hline $\mathrm{X} 6$ & -.1308 & -.1226 & -.0186 & .7817 & -.0529 \\
\hline $\mathrm{X} 7$ & .6409 & .1163 & .2898 & -.1420 & .0701 \\
\hline $\mathrm{X} 8$ & .5629 & .3467 & -.2804 & .1505 & .0841 \\
\hline X9 & -.1895 & -.0296 & .2866 & .7444 & -.0227 \\
\hline $\mathrm{X} 10$ & .5574 & .1776 & -.1842 & -.0909 & .0448 \\
\hline X11 & .1651 & .5405 & .2029 & .2767 & .0103 \\
\hline $\mathrm{X} 12$ & .3636 & .0705 & .4813 & -.1823 & .1036 \\
\hline $\mathrm{X} 13$ & .1745 & .5911 & -.0414 & -.2073 & -.1892 \\
\hline X14 & -.0265 & .1073 & .6379 & .0033 & .1304 \\
\hline X15 & .1668 & .3247 & .5802 & .1632 & -.0857 \\
\hline $\mathrm{X} 16$ & .1253 & -.0018 & .6093 & .1828 & -.0568 \\
\hline $\mathrm{X} 17$ & .4835 & -.0311 & -.0950 & -.0957 & -.5758 \\
\hline $\mathrm{X} 18$ & .4518 & .0398 & -.0399 & -.0131 & .7016 \\
\hline X19 & .3812 & -.1136 & .1067 & -.1533 & .6550 \\
\hline
\end{tabular}

Source: Data Processing Results

The next step is to determine the dominant variables that form factors in succession, to be considered and renewed on the perception of a user's desire before they travel using public passenger transport from Medan to Pematang Siantar. Each factor has been identified and named based on the factor loading of the variable. The number of factors shows a correlation between one variable and another when a factor is formed. The magnitude of the factor loading of each variable is shown in Table 1.

An initial variable is said to be significant and can be grouped into a factor when it has an absolute value of factor loading $\geq 0.3$. Variables that make up the factor with the highest factor loading are the most dominant variables in that factor. Likewise, the greatest-value factor of the two factors indicates the dominant variables of the two factors, thus the last variable. When a distortion has an absolute value of factor loading $\leq 0.3$, then the variable will be ignored because it is considered insignificant.

\subsubsection{Comfort factor}

This factor is the most important factor influencing passenger's judgment regarding the transport mode to use from Medan to Pematang Siantar. It involves 6 initial variables having an absolute value of factor loading $\geq 0.3$.

The dominant variables that make up this factor, as shown in Table 1 above, are the employee's hospitality at the terminal and vehicle workers on the route $\left(\mathrm{X}_{14}\right)$, airflow system and temperature regulation in the vehicle $\left(\mathrm{X}_{16}\right)$, seat comfort $\left(\mathrm{X}_{1} 2\right)$ in the vehicle $\left(\mathrm{X}_{15}\right)$.

Values in Table 1 above show that these six initial variables have a high level of interdependence on each other. These six initial variables were taken from the comfort factor, namely $\mathrm{X}_{14}, \mathrm{X}_{16}, \mathrm{X}_{12}, \mathrm{X}_{15}, \mathrm{X}_{13}$, and $\mathrm{X}_{17}$. A study [13] states that one of the main traits of transport is comfort and pleasure. In this study, there are several initial variables that show the fun factor combined with other factors. The comfort factor has the highest variance of $3.7398 \%$. This means that $3.7398 \%$ of the respondents' responses about the route were influenced by the comfort factor.

The overall average value of the comfort factor shown by the initial variable is $\frac{X_{14}+X_{16}+X_{12}+X_{15}+X_{18}+X_{17}}{6}=3.7787$. This indicates that the comfort factor is very important for every passenger. Therefore, passenger transport service operators who pass through the Medan-Pemantar Siantar route should consider and pay attention to the comfort factor of the service.

\subsubsection{Accessibility factor}

This factor is the fourth most important factor influencing an individual's judgment regarding the transport mode to be used from Medan to Pematang Siantar . It involves 2 initial variables that have absolute value of factor loading $\geq 0.3$. 
The dominant variables that make up this factor are described as follows:

$\mathrm{X}_{18}$ : Convenience to the departure point is the convenience to get to the terminal at the departure point. It has a factor loading of 0.398 (Table 1).

$\mathrm{X}_{19}$ : Facilities that reach the final destination from the terminal at the end of the route. It has a factor loading of 0.1136 .

These values indicate that the two initial variables have high dependence on each other. Both variables are derived from the comfort and accessibility factors, associated with the convenience of access to transport services (both infrastructure and transport facilities) from origin to destination and from vehicle stopping to final destination. These two factors are also called convenience factors.

The accessibility factor has a variance of $1.9508 \%$, obtained from the assessments carried out by passengers influenced by convenience factors (Table 1). The overall average value of the accessibility factor shown by the initial variables is $\frac{X_{18}+X_{19}}{2}=3.9336$ and indicates that this factor is considered to be very important for passengers.

\subsubsection{Cost factor}

This factor is the third most important factor influencing an individual's judgment regarding the transport mode to use from Medan to Pematang Siantar. It involves two initial variables that have an absolute value of the factor loading $\geq 0.3$.

The dominant variables that form this third factor are described:

$\mathrm{X}_{6}$ : The cost of the main route is the total cost that the service user must pay for the journey from Medan to Pematang Siantar. It has a factor loading of 0.186 (Table 1).

$\mathrm{X}_{7}$ : The additional cost is the total cost incurred by travellers such as the cost of transport within the city from the original destination to another, parking and so on. It has a factor loading of 0.2898 .

This means that the above variables are the third most important factor that can influence the respondents' decision while travelling through the Medan-Pematang Siantar route. These values indicate that the two variables have a high degree of mutual dependence on each other, and it appears that they are more dominated by cost factor, such as the cost incurred by the passenger from departure to the end destination.

The cost factor has a variance of $5.4330 \%$ derived from assessment of respondents influenced by the cost factor. The overall average value of the cost factor shown by the initial variables is $\frac{X_{6}+X_{7}}{2}=4.1638$ which indicates that this factor is considered important for travellers.

\subsubsection{Time factor}

This factor is the second most important factor influencing an individual's judgment regarding the transport mode to use from Medan to Pematang Siantar. It involves four initial variables that have absolute value of factor loading $\geq 0.3$.

The dominant variables that make up this factor are shown:

$\mathrm{X}_{4}$ : The passage of time is either found to deviate from the average travel time or not. It has a factor loading of 0.3272

$\mathrm{X}_{2}$ : The additional route time is the time it takes to travel from home to departure (in Medan) and from transit (in Pematang Siantar ) to the final destination. It has a factor loading of 0.0869 .

$\mathrm{X}_{1}$ : The main route time is the time taken to travel from the departure point to the transit point. It has a factor loading of 0.3117 .

$\mathrm{X}_{3}$ : The transfer time is the time taken during the change of vehicle and while waiting for the vehicle to depart. It has a factor loading of 0.3615 .

This means that the above four variables are the second most important factor that can influence the respondents' decision when travelling through the Medan-Pematang Siantar route.

This suggests that these four initial variables have high interdependence on each other. These four initial variables are taken from the time factor, which is related to the total travel period (from departure to the final destination).

This factor has a variance of $18.6220 \%$, obtained from responses of respondents influenced by time factor. The overall average value of the time factor shown by the initial variables is $\frac{X_{4}+X_{2}+X_{1}+X_{3}}{4}=4.0830$ which indicates that this factor is very important for travellers.

Therefore, passenger transport service operators on the Medan-Pematang Siantar route should consider and pay attention to the time factor of their service product.

\subsubsection{Safety factor}

This factor is the last factor influencing an individual's judgment regarding the transport mode to take from Medan to Pematang Siantar. It involves five initial variables that have absolute value of factor loading $\geq 0.3$.

The dominant variables that make up this factor are shown:

$\mathrm{X}_{8}$ : Passenger safety is the possibility of road safety, which can lead to human security. It has a factor loading of 0.0841 (Table 1).

$\mathrm{X}_{10}$ : Security from possible criminal offenses against passengers, such as theft. It has a factor loading of -0.0448 .

$\mathrm{X}_{5}$ : Daily traffic frequency is the level of routing frequencies performed by the daily transport modes involved. It has a factor loading of -0.0100 . 
$\mathrm{X}_{9}$ : Baggage damage caused by carelessness or tremors during the trip. It has a factor loading of -0.0227 .

$\mathrm{X}_{11}$ : Safety equipment refers to the facilities that are available for personal safety in an emergency. It has a factor loading of 0.0103 .

This means that the above five variables are the last factor that can influence the respondents' decision regarding the trip from Medan to Pematang Siantar . The values indicate that these five variables have a high degree of mutual dependence on each other. Four of these five variables are derived from the safety factor, relating to the level of security of passengers and baggage throughout the trip, including while waiting at the departure point. Only one variable is derived from the time factor.

Safety factor has a variance of $6.1619 \%$, which is derived from responses of respondents influenced by safety factors. The overall average value of the safety factor shown by the initial variables is $\frac{X_{8}+X_{0}+X_{5}+X_{9}+X_{11}}{5}=3.8560$ and indicates that this factor is considered to be very important for travellers. Therefore, entrepreneurs should consider and pay attention to the safety factor of their passengers.

\section{Conclusion}

This study uses factor and cluster analyses. Analysis of factors was performed to determine the most dominant out of five factors. The cluster analysis was used to determine advantages and disadvantages of five modes of transport, namely taxi, trade rail, economy bus, mini bus, and executive bus.

This study aimed to find out the perceptions of users of Medan-Pematang Siantar route. The results of the study show that there are five dominant factors that are considered before service users decide on the mode of transport to use, namely comfort factor, which is the most important consideration, followed by time factor, cost factor, accessibility factor, and safety factor.

The average advantages of the five modes of transport along the Medan-Pematang Siantar route is seen from the five factors of comfort, time, cost, accessibility and safety based on the market segments that each one possesses. So, generally, the most favored are taxis, executive buses, mini buses, trade trains and economic buses.

\section{References}

[1] AZIS, I. J. Regional economics and some of its applications in Indonesia (in Bahasa Indonesia). Jakarta: LP-FEUI, 1994. ISBN 979-814-035-4.

[2] The Ministry of Transportation of Indonesia. Profile of Medan, Bertari City. Development Planning Agency at SubNational Level. Medan: Pemko Medan. 2003.

[3] SCHIFFMAN, L. G. Consumer behaviour. Prentice Hall, 1997. ISBN 072-480-220-7.

[4] MOWEN J. C., MINOR, M. Consumer Behavior (in Bahasa Indonesia). Vol. 1, 5th ed., Jakarta: Erlangga, 2002. ISBN 979-688-318-x.

[5] MOWEN J. C., MINOR, M. Consumer behavior (in Bahasa Indonesia). Vol. 2, 5th ed. Jakarta: Erlangga, 2002. ISBN 79-688-319-8.

[6] KOTLER, P. Marketing management: analysis, planning, implementation, and control. 9. ed. Upper Saddle River, NJ: Prentice Hall International, 1997. ISBN 013-261-363-8.

[7] DRUCKER, P. The practice of management. Allied Publishers, 1975. ISBN 817-023-030-6.

[8] LOUDON, D. L., DELLA BITTA, A. J. Consumer behvior: Concepts and applications. 4. ed. New York: Singapore: McGraw-Hill, 1993. ISBN 007-112-511-6.

[9] SUMARWAN, U. Consumer behavior: Theory and its application in marketing (in Bahasa Indonesia). Jakarta Selatan: Penerbit Ghalia Indonesia, 2009. ISBN 979-450-451-3.

[10] PETER, J. P., OLSON, J. C. Consumer behaviour and marketing strategy (in Bahasa Indonesia). Jakarta: Erlangga, 2000. ISBN 979-411-736-6.

[11] MURRAY, K. B. A Test of services marketing theory: Consumer information acquisition activities. Journal of Marketing [online]. 1991, 55(1), p. 10-25. ISSN 0022-2429. Available from: https://doi.org/10.2307/1252200

[12] MIRO, F. Transportation Planning. Jakarta: Erlangga, 2004. ISBN 9789790993112.

[13] MANHEIM, L. M. Fundamentals of transportations systems analysis. Vol. 1: Basic conseps. London: MIT Press, 1979. ISBN 978-0262131292.

[14] KUSBIANTORO, X. A Study of urban mass transit performance: consep measurement and explanation. Ph.D. dissertation. University of Pensylvania, Philadelphia, 1985.

[15] BEN-AKIVA, M. E., LERMAN, S. R. Discrete choice analysis: Theory and application to travel demand. Cambridge, MA: MIT Press, 1985. ISBN 978-0262022170.

[16] BEN-AKIVA, M. E., LERMAN, S. R. Discrete choice analysis: Theory and application to travel demand. Cambridge, MA: MIT Press, 1985. ISBN 978-0262022170. 